\title{
Post-translational modifications of tubulin and microtubule stability in adult rat ventricular myocytes and immortalized HL-1 cardiomyocytes
}

Souad Belmadani, ${ }^{1}$ Christian Poüs, ${ }^{2}$ Rodolphe Fischmeister ${ }^{1}$ and Pierre-François Méry ${ }^{1, \$}$

${ }^{1}$ Laboratoire de Cardiologie Cellulaire et Moléculaire, INSERM U-446; ${ }^{2}$ Laboratoire de Biochimie et de Biologie Cellulaire, EA 1595; ${ }^{1,2}$ IFR-75 Institut de Signalisation et Innovation Thérapeutique, Université Paris-Sud, Faculté de Pharmacie, Châtenay-Malabry, France

\$Present address: Inserm U-469, CCIPE, 141 rue de la Cardonille, F-34094 Montpellier Cedex 5, France

Address for offprints: S. Belmadani, INSERM U-446, Université Paris-Sud, Faculté de Pharmacie, F-92296 Châtenay-Malabry Cedex, France (E-mail:

belmadani_souad@hotmail.com) 


\section{Abstract}

Little is known about the subcellular distribution and the dynamics of tubulins in adult cardiac myocytes although both are modified during cardiac hypertrophy and heart failure. Using confocal microscopy, we examined post-translational modifications of tubulin in fully differentiated ventricular myocytes isolated from adult rat hearts, as well as in immortalized and dividing HL-1 cardiomyocytes. Detyrosinated Glu- $\alpha$-tubulin was the most abundant posttranslationally modified tubulin found in ventricular myocytes, while acetylated- and $\Delta_{2}-\alpha-$ tubulins were found in lower amounts or absent. In contrast, dividing HL-1 cardiomyocytes exhibited high levels of tyrosinated or acetylated $\alpha$-tubulins. A mild nocodazole treatment (0.1 $\mu \mathrm{M}, 1$ hour) disrupted microtubules in HL-1 myocytes, but not in adult ventricular myocytes. A stronger treatment $(10 \mu \mathrm{M}, 2$ hours $)$ was required to disassemble tubulins in adult myocytes. Glu- $\alpha$-tubulin containing microtubules were more resistant to nocodazole treatment in HL-1 cardiomyocytes than in ventricular myocytes. Endogenous activation of the cAMP pathway with the forskolin analog L858051 $(20 \mu \mathrm{M})$ or the $\beta$-adrenergic agonist isoprenaline $(10 \mu \mathrm{M})$ disrupted the most labile microtubules in HL-1 cardiomyocytes. In contrast, isoprenaline $(10 \mu \mathrm{M})$, cholera toxin $\left(200 \mathrm{ng} / \mathrm{ml}, \mathrm{a} \mathrm{G}_{\mathrm{S}}\right.$-protein activator), L858051 $(20 \mu \mathrm{M})$ or forskolin $(10 \mu \mathrm{M})$ had no effect on the microtubule network in ventricular myocytes. In addition, intracellular $\mathrm{Ca}^{2+}$ accumulation induced either by thapsigargin $(2 \mu \mathrm{M})$ or caffeine $(10 \mathrm{mM})$ did not modify microtubule stability in ventricular myocytes. Our data demonstrate the unique stability of the microtubule network in adult cardiac myocytes. We speculate that microtubule stability is required to support cellular integrity during cardiac contraction.

Key words: microtubules, cytoskeleton, heart, myocyte, cell differentiation, cyclic AMP 


\section{Introduction}

Microtubules are involved in cell structure as well as in various cellular functions, such as mitosis and intracellular transport [1-3]. Microtubules constitute a dynamic network, as evidenced by the fact that microtubules plus ends switch between growing and shrinking states. This process, termed dynamic instability, is thought to result mainly from the stochastic gain or loss of a stabilizing GTP [4, 5]. However, the dynamic behavior of microtubules is not uniform as various microtubule subpopulations enriched in posttranslationally modified tubulins exhibit low dynamic rates. The dynamic behavior of microtubules regulates various cellular functions [6, 7]. In the heart, an increase in microtubule content leads to a reduction in contractile performances [8, 9]. Moreover, the microtubule network is modified during cardiac hypertrophy and heart failure [10-12]. Interestingly, the stable pool of microtubules was shown to be selectively involved in the spontaneous beating activity of neonatal cardiac myocytes [9]. In addition, chemical stabilization of microtubules reduces the amplitudes of both contraction and $\mathrm{Ca}^{2+}$ transient in adult ventricular myocytes [13], while chemical depolymerization exerts opposite effects [14, $15]$.

A wealth of covalent post-translational modifications of $\alpha$ - and $\beta$-tubulin subunits have been identified in stable microtubules. Acetylation of $\alpha$-tubulin is a common modification which was reported to occur in stable, long-lived microtubules [16, 17]. Acetylated $\alpha$-tubulin is abundant during neonatal cardiac development, is reduced in the adult heart [18], but its biological function remains unknown. Detyrosination of $\alpha$-tubulin (which yields Glu- $\alpha$-tubulin) is another modification which occurs in stable microtubules during neonatal cardiac development $[9,16,18]$. Although its role has not been clearly demonstrated yet, it might contribute to the interaction between microtubules and intermediate filaments as 
demonstrated in fibroblasts $[19,20]$. The penultimate glutamate residue of $\alpha$-tubulin can also be removed by a similar carboxypeptidase pathway, resulting in $\Delta_{2}$ - $\alpha$-tubulin, an irreversiblymodified tubulin that accumulates in the stable pool of neuronal microtubules [21]. While the distribution of $\Delta_{2}$ - $\alpha$-tubulin is altered during cardiac insufficiency [12, 22], its specific role in the normal heart also remains to be established.

As tubulin post-translational modifications are thought to result from microtubule stabilization, the latter ought to be regulated at the cellular level by various signaling processes. Indeed, microtubule dynamics are affected by second messenger pathways, some of which, like the cAMP pathway and the $\mathrm{Ca}^{2+}$ pathway, play a major role in the control of cardiac contractility. For instance, cAMP-dependent protein kinase binds to microtubules and reduces their nucleation activity, via phosphorylation of MAP2, the microtubule associated protein $2[23,24]$. Inhibition of adenylyl cyclase antagonizes the effect of colchicine on the Ltype $\mathrm{Ca}^{2+}$ current in adult cardiac myocytes [14]. In response to an increase in $\mathrm{Ca}^{2+}$, the $\mathrm{Ca}^{2+}-$ calmodulin kinase also depolymerizes microtubules [25]. Similarly, intracellular $\mathrm{Ca}^{2+}$ overload disrupts microtubules in neonatal cardiac myocytes [26]. GTP-binding proteins can also modify microtubules dynamics [27, 28]. Indeed, the interaction between tubulin and G $\beta \gamma$ promotes microtubule assembly [29], while $\mathrm{G}_{\mathrm{i} 1} \alpha, \mathrm{G}_{\mathrm{s}} \alpha$, and $\mathrm{G}_{\mathrm{o}} \alpha$ activate the GTPase function of tubulin, inhibit microtubule assembly and accelerate microtubule dynamics [30].

While all these studies suggest that microtubule stability affects cardiac performances, little is known about the post-translational modifications of tubulins in relation with their stability in the adult cardiomyocytes. In this work, we studied the post-translational modifications of $\alpha$-tubulin and the microtubule stability in ventricular myocytes freshly isolated from adult rat hearts. We also investigated the effects of intracellular $\mathrm{Ca}^{2+}$ accumulation and adenylyl cyclase pathway activation on the polymerization of tubulins. For a comparison, these characteristics were studied in HL-1 cardiomyocytes, a cell line derived 
from adult mouse atrial myocytes induced to proliferate indefinitely by SV40 large T antigen [31], i.e. a cell line that has the ability, unlike adult myocytes, to divide in vitro. 


\section{Materials and methods}

The investigation conforms with the European Community guiding principles in the care and use of animals (86/609/CEE, $C E$ Off $J \mathrm{n}^{\circ} \mathrm{L} 358,18$ December 1986) and the French decree n87/748 of October 19, 1987 (J Off République Française, 20 October 1987, pp. 1224512248). Authorisations to perform animal experiments according to this decree were obtained from the French Ministère de l'Agriculture et de la Forêt (n04226, April 12, 1991).

\section{Isolation of cardiac myocytes}

Male Wistar rats (160-275 g) were anaesthetized by intraperitoneal injection of urethane $(2 \mathrm{~g} / \mathrm{Kg})$ and heparin $(2.5 \mathrm{mg} / \mathrm{Kg})$. Myocytes were dispersed using collagenase A $(0.255$ $\mathrm{mg} / \mathrm{ml}$, Boehringer-Manheim, Germany) as previously described [32]. At the end of the perfusion, atria and ventricles were separated, and ventricular myocytes were resuspended step by step, in a $1 \mathrm{mM} \mathrm{Ca}^{2+}$ containing solutions, which consisted in $(\mathrm{mM}): \mathrm{NaCl} 117, \mathrm{KCl}$ 5.7, $\mathrm{NaHCO}_{3}$ 4.4, $\mathrm{KH}_{2} \mathrm{PO}_{4}$ 1.5, $\mathrm{MgCl}_{2}$ 1.7, $\mathrm{CaCl}_{2}$ 1, creatine 10, taurine 20, HEPES 21, adjusted to $\mathrm{pH} 7.4$ with $\mathrm{NaOH}\left(37^{\circ} \mathrm{C}\right)$. Isolated myocytes were attached onto laminin coated glass coverslips in a humidified incubator at $37^{\circ} \mathrm{C}$, for 2 and occasionally 4 hours with no difference in results. The myocytes were then processed as described below.

\section{HL-1 cell line}

HL-1 cardiomyocytes (passage 71) were obtained from Dr. W. C. Claycomb (Louisiana State University Health Science Center, New Orleans, LA, USA) who first established and characterized the cell line [31]. HL-1 cells were handled as previously described [31]. HL-1 cardiomyocytes were grown onto a matrix of gelatin (0.02\%) (Sigma, St Quentin-Fallavier, 
France) plus fibronectin $(12.5 \mu \mathrm{g} / \mathrm{ml}$, Sigma), into a medium consisting of Ex cell 320 medium (JRH Biosciences, Lenexa, USA), 10\% fetal bovine serum (Life Technologies, Cergy Pontoise, France), 4 mM L-glutamine (Life Technologies), $10 \mu \mathrm{M}$ norepinephrine (Sigma), $10 \mu \mathrm{M}$ penicillin-streptomycin (Life Technologies), $10 \mu \mathrm{g} / \mathrm{ml}$ insulin (Life Technologies), 50 $\mu \mathrm{g}$ endothelial cell growth supplement (Upstate Biotechnology, Lake Placid, NY, USA) and 1 $\mu \mathrm{M}$ retinoic acid (Sigma). The cells were incubated at $37^{\circ} \mathrm{C}$, in $95 \% \mathrm{O}_{2}-5 \% \mathrm{CO}_{2}$ at a relative humidity of $95 \%$. The cells were plated 2 days before an experiment.

\section{Immunocytochemistry}

Cells attached onto glass coverslips were rinsed twice in phosphate-buffered saline solution PBS (Invitrogen, Cergy Pontoise, France) during $5 \mathrm{~min}$, fixed in methanol at $-20^{\circ} \mathrm{C}(5 \mathrm{~min})$, washed again in PBS (5 min, three times), and stored overnight at $4{ }^{\circ} \mathrm{C}$ in $\mathrm{PBS}+5 \%$ bovine serum albumin (BSA, Sigma). Next, they were incubated with primary antibodies $\left(1 \mathrm{~h}, 37^{\circ} \mathrm{C}\right)$, washed with PBS (5 min, three times), and incubated $\left(1 \mathrm{~h}, 37^{\circ} \mathrm{C}\right)$ with FITC-conjugated or a mixture of FITC- and TRITC-conjugated antibodies (full-length or Fab fragments) for single and double-labeling experiments, respectively. After three washes, the coverslips were mounted in Mowiol antifadent mounting medium (Calbiochem, Meudon, France) and examined with a confocal microscope (Zeiss, LSM 510, Germany).

\section{Antibodies}

The polyclonal antibody to Glu- $\alpha$-tubulin (L3) and monoclonal antibody to $\Delta_{2}$-tubulin were generous gifts from Dr. L. Paturle-Lafanechère (Laboratoire du Cytosquelette, INSERM U366, Grenoble, France). The four monoclonal antibodies raised against $\alpha$-tubulin (clone DM1 
A), $\beta$-tubulin (clone TUB 2.1) tyrosinated $\alpha$-tubulin (clone TUB-1A2), and acetylated $\alpha$ tubulin (clone 6-11B-1) were from Sigma. The secondary antibodies (rhodamine-conjugated goat anti-mouse, fluorescein-conjugated anti mouse, rhodamine conjugated anti-rabbit) were purchased from Sigma. For the detection of centriolar proteins, we used a monoclonal antibody raised against polyglutamylated tubulin (clone GT335) kindly provided by Pr. Philippe Denoulet (CNRS FRE2219, Université Paris VI, Paris, France). The specificity of the antibodies used here has been assessed previously by Western blot analysis of rat cardiac ventricle homogenates [12].

\section{Drugs}

Cholera toxin was from Sigma, forskolin and L858051 (a forskolin analog) were from Calbiochem (Meudon, France), caffeine was from Merck (Strasbourg, France), thapsigargin, isoprenaline and A23187 were from Sigma. Nocodazole (Sigma) was kept as a $10 \mathrm{mM}$ solution in dimethylsulfoxide (DMSO) at $-20^{\circ} \mathrm{C}$ and diluted before use. Laminin (Sigma) was dissolved in the storage medium at $166 \mu \mathrm{g} / \mathrm{ml}$, and stored at $-80^{\circ} \mathrm{C}$ until single use.

\section{Confocal microscopy}

Cells were double stained for immunofluorescence using FITC and TRITC-conjugated secondary antibodies. Optical sections series were obtained with a confocal scanning laser LSM 510 (Zeiss, Germany). Images were acquired with a 63x:1.4 oil objective (Zeiss). The starting optical sections $(0.0 \mu \mathrm{m})$ was defined as the level of contact between the cells and the cover slips. 


\section{Results}

Subcellular localization of $\alpha$ - and $\beta$-tubulins in isolated ventricular myocytes

Cellular $\alpha$ - and $\beta$-tubulin immunolabelings were examined by confocal microscopy in ventricular cardiomyocytes isolated from rat hearts (Fig. 1). As shown in the Z-series of Fig. 1A, $\alpha$-tubulin was mostly organized as thin tortuous polymers throughout the cytoplasm, although some of the tubules appeared short and curly. Densely packed $\alpha$-tubulin labeling surrounded the nuclei with a circumnuclear distribution. It appeared to radiate transversally and longitudinally from the perinuclear areas towards the sarcolemma. B-tubulin immunolabeling revealed a pattern very similar to that of $\alpha$-tubulin (Fig. 1B). When normalized to the maximum values of immunofluorescence, $\alpha$ - and $\beta$-tubulin exhibited superimposable distributions throughout the myocyte (Fig. 1C). Labeling with $\alpha-$ and $\beta$ tubulin antibodies did not elicit any microtubule-organizing centers in cardiac myocytes, although the anti-polyglutamylated tubulin antibody gave a juxtanuclear signal that was evocative of a centriolar labeling (Fig. 2E). This data is representative of ventricular myocytes isolated from 4 hearts.

(Figure 1 near here)

Post-translational modifications of $\alpha$-tubulin in isolated ventricular myocytes

The post-translational modifications of $\alpha$-tubulin were then studied in ventricular myocytes from 10 different rat hearts (Fig. 2). At the single cell level, tyrosinated $\alpha$-tubulin (Fig. 2B) 
and detyrosinated $\alpha$-tubulin (Glu- $\alpha$-tubulin, Fig. 2C) immunolabelings were comparable in abundance, intensity and subcellular distribution to that of total $\alpha$-tubulin labeling (Fig. 2A and Fig. 1). In contrast, most $\Delta_{2}$ - $\alpha$-tubulin immunolabeling concentrated into the perinuclear region, and was occasionally observed as very short tubules within the cytoplasm (Fig. 2D, data from 4 hearts). Interestingly, the anti-acetylated $\alpha$-tubulin antibody did not label at all adult ventricular myocytes in 9 out of 10 hearts (Fig. 2F). The level of immunofluorescence in these experiments was identical to that observed in the negative control experiments where the primary antibody had been omitted from the labeling procedure (Fig. 2G and H). However, acetylated $\alpha$-tubulin was observed in a small subset of myocytes (less than 10\%) from one heart, where it localized to the perinuclear region and the cytoplasm as short and faint tubules(data not shown).

(Figure 2 near here)

Effect of depolymerizing drugs on microtubules in ventricular cardiac myocytes

Tubulin turnover on and off microtubules can be assessed by studying the effects of nocodazole, a microtubule-disrupting agent. Incubation of rat ventricular myocytes with a low concentration of nocodazole (1 $\mathrm{nM}$ for $1 \mathrm{~h}$, Fig. 3B) did not significantly modify the subcellular distribution of either $\alpha$ - or B-tubulin (compare Fig. 3A and B). In addition, this treatment had no effect on the subcellular distribution of Glu- $\alpha$-tubulin (Fig. 3A and B), an isoform previously associated with stable microtubules in neonatal cardiac myocytes [16]. Similarly, an intermediate concentration of nocodazole $(0.1 \mu \mathrm{M}$ for $1 \mathrm{~h})$ did not significantly alter the distribution of total $\alpha$ - or $\beta$-tubulins as well as Glu- $\alpha$-tubulin (compare Fig. 3A and C). Similar results were found in ventricular myocytes isolated from 6 different hearts. 
(Figure 3 near here)

Higher concentrations of nocodazole $(10 \mu \mathrm{M}$ for $2 \mathrm{~h}$ ) induced the depolymerization of the dynamic microtubule subset, leaving the stable pool intact (Fig. 3D). Under this condition, $\alpha$ - and $\beta$-tubulins, as well as Glu- $\alpha$-tubulin appeared as short and curly tubules randomly distributed within the cell. Some perinuclear labeling could still be visualized, although it was less dense and organized. When nocodazole treatment was prolonged to $4 \mathrm{~h}$, the residual labeling of short microtubule fragments (less than 10 per cell) could be detected, mainly in the perinuclear region of the myocytes (data not shown).

In order to confirm these findings, the effect of another microtubule disrupting agent, colchicine, was examined. While microtubules fully collapsed in the cytoplasm and the perinuclear region upon prolonged treatments with colchicine $(1 \mu \mathrm{M}, 6-7 \mathrm{~h})$, these structures remained intact during shorter treatments with the $\operatorname{drug}(1 \mu \mathrm{M}$ for up to $4 \mathrm{~h}$, data not shown).

Effects of $\mathrm{Ca}^{2+}$ and cAMP on microtubules in ventricular myocytes

The cAMP pathway plays a central role in the regulation of the excitation-contraction coupling in cardiac myocytes. We therefore examined whether activation of the cAMP cascade modifies the subcellular distribution of microtubule isoforms in rat ventricular myocytes. As shown in Fig. 4, treatment of rat ventricular myocytes with $20 \mu \mathrm{M}$ L858051, a forskolin analog which directly activates adenylyl cyclase, for up to $1 \mathrm{~h}$ did not alter the subcellular distribution of either $\alpha$-tubulin (compare Fig. 4A and B, upper panels), Glu- $\alpha-$ tubulin (compare Fig. 4A and B, lower panels), or $\beta$-tubulin (not shown) in adult ventricular myocytes. A similar treatment with forskolin $(10 \mu \mathrm{M}, 1 \mathrm{~h})$ had also no effect on microtubules 
(data from 6 hearts, not shown). The microtubule network was also unchanged in cardiomyocytes exposed to the $\beta$-adrenergic agonist isoprenaline $(10 \mu \mathrm{M}, 1 \mathrm{~h})$, which activates adenylyl cyclase via the GTP-binding protein, $G_{s}$ (compare Fig. 4A and C). Likewise, incubations with cholera toxin $(200 \mathrm{ng} / \mathrm{ml}$, for $2-4 \mathrm{~h})$, an activator of $\mathrm{G}_{\mathrm{s}}$, had no effect on microtubules in ventricular myocytes (data not shown).

(Figure 4 near here)

Intracellular $\mathrm{Ca}^{2+}$ accumulation is known to induce the disassembly of existing microtubules and to inhibit microtubule assembly in various cell types, including neonatal cardiac myocytes in culture. Therefore, we examined the status of the microtubule network in the presence of thapsigargin and caffeine, two $\mathrm{Ca}^{2+}$-elevating agents, in rat ventricular myocytes. As shown in Fig. 4E, incubation with caffeine (10 mM, $15 \mathrm{~min})$ did not modify $\alpha-$ tubulin immunostaining in the cytoplasm and in the perinuclear region of isolated cardiomyocytes (compare Fig. 4D and E, upper panels). Furthermore, the caffeine treatment did not modify the distribution of Glu- $\alpha$-tubulin in these cells (compare Fig. 4D and E, lower panels). In another series of experiments, a treatment with thapsigargin ( $2 \mu \mathrm{M}, 10 \mathrm{~min})$ was also without effects on the distribution of both $\alpha$-tubulin and Glu- $\alpha$-tubulin in cardiac myocytes (compare Fig. 4D and F). Longer treatments with either drugs induced cellular contracture (data not shown).

Subcellular localization of $\alpha$ - and $\beta$-tubulins in HL-1 cardiomyocytes

Next we examined the microtubule network in HL-1 cardiomyocytes, a mouse cell line which has the ability, unlike adult myocytes, to divide in vitro. This cell line exhibits many features 
of the neonatal cardiac myocytes [31]. An anti $\alpha$-tubulin staining demonstrated an abundant network of elongated tubules distributed throughout the cytoplasm, and decorating the perinuclear region in a latero-nuclear configuration (Fig. 5A). Some tortuous $\alpha$-microtubules were also observed. A microtubule organizing center was routinely identified, as a densely packed area from which microtubules radiate throughout the cytoplasm (Fig. 5A). We also investigated ß-tubulin immunolabeling in HL-1 cardiomyocytes (Fig. 5B). B-tubulin colocalized with $\alpha$-tubulin in the HL-1 myocytes (Fig. 5B and C). Serial sections in the Z-axis of the HL-1 myocytes demonstrated that the subcellular distributions of $\alpha$ - and $\beta$-tubulins were identical along the depth of cell (Fig. 5D). There was no background fluorescence in HL-1 cardiomyocytes incubated with the secondary antibodies alone (Fig. 5E and F). Similar results were obtained in 4 independent cultures of HL-1 myocytes.

(Figure 5 near here)

As shown in Fig. 6A, tyrosinated $\alpha$-tubulin was very abundant in HL-1 cardiomyocytes, and almost entirely overlapped total $\alpha$-tubulin labeling (3 cultures). Tyrosinated $\alpha$-tubulin organized preferentially into straight and thin polymers. In contrast, Glu- $\alpha$-tubulin was much less abundant, and organized into tortuous and thicker structures, evocative of microtubule bundles (Fig. 6B, 2 cultures). Double labeling experiments demonstrated that the non-selective anti $\alpha$-tubulin antibody DM1A did not decorate strongly these thicker Glu- $\alpha$-tubulin containing structures. This result suggested that other $\alpha$-tubulin modifications might be excluded from Glu- $\alpha$-tubulin containing microtubules. A microtubule organizing center was also observed with Glu- $\alpha$-tubulin antibody (Fig. 6B). As shown in Fig. 6C, most $\alpha$-tubulin was also acetylated in HL-1 cells (4 cultures). Acetylated, tyrosinated and 
detyrosinated $\alpha$-tubulins were all found in the microtubule organizing center of HL-1 cardiomyocytes.

(Figure 6 near here)

Effect of depolymerizing drugs on microtubules in HL-1 cardiomyocytes

Like in adult ventricular myocytes, we examined microtubule dynamics in HL-1 cardiomyocytes using a treatment with a low concentration of nocodazole. Short-term treatment with $0.1 \mu \mathrm{M}$ nocodazole during $1 \mathrm{~h}$ induced a dramatic microtubule disruption, suggesting that most of the microtubule network is dynamic in HL-1 cells (Fig. 7A to D, 4 cultures). Accordingly, the acetylated- $\alpha$-tubulin staining was strongly reduced by nocodazole, as only few acetylated tubules resisted to the drug (Fig. 7E and F, 4 cultures). The intensity of the Glu- $\alpha$-tubulin staining was not reduced by the depolymerizing agent (Fig. 7G and H, 2 cultures). Thus, like in neonatal myocytes $[9,18]$, Glu- $\alpha$-containing microtubules characterize a nocodazole-resistant network in HL-1 cardiomyocytes.

(Figure 7 near here)

Effect of cAMP and $\mathrm{Ca}^{2+}$ on microtubules in $\mathrm{HL}-1$ cardiomyocytes

As in adult rat ventricular myocytes, we first examined the effect of L858051 on microtubule isoform distribution in HL-1 cells. As shown in Fig. 8, a short-term treatment with L858051 (20 $\mu \mathrm{M}, 20 \mathrm{~min}$ ) induced a dramatic disassembly of the microtubule network similar to that observed with nocodazole, indicating that cAMP is actually involved in controlling 
microtubule dynamics in HL-1 cardiomyocytes (Fig. 8A-D, 4 cultures). A longer incubation with L858051 (up to 1h) had no additional effects (data not shown). A treatment with the cAMP-elevating agent also disrupted most, if not all, acetylated $\alpha$-tubulin network (Fig. 8E and $F, 4$ cultures), in agreement with the fact that acetylated $\alpha$-tubulin containing microtubules are dynamic in HL-1 cells (see Fig. 7). In contrast, the Glu- $\alpha$-tubulin staining was only marginally affected by L858051 (Fig. 8G and H, 2 cultures).

The effect of isoprenaline was also examined in HL-1 myocytes. In three experiments, a short-term treatment with isoprenaline $(10 \mu \mathrm{M}, 30 \mathrm{~min})$ induced a dramatic breakdown of the filamentous staining for $\alpha$-tubulin, confirming the involvement of cAMP in the regulation of microtubule dynamics in these cells (data not shown).

(Figure 8 near here)

To examine how intracellular $\mathrm{Ca}^{2+}$ affects microtubule organization in HL-1 myocytes, the cells were exposed to the $\mathrm{Ca}^{2+}$ ionophore A23187. The number of $\alpha$-tubulin filaments was strongly reduced by a short-term treatment with A23187 (3 $\mu \mathrm{M}, 20$ min, data not shown). This effect was time-dependent, and only few and short microtubules were observed after a 150 min exposure to the $\mathrm{Ca}^{2+}$ ionophore (data not shown). 


\section{Discussion}

In this study, we demonstrate that adult, differentiated cardiomyocytes differ in many aspects from dividing cardiomyocytes in the subcellular organization and stability of the microtubule network: 1) detyrosinated Glu- $\alpha$-tubulin was the most abundant post-translationally modified tubulin isoform found in adult ventricular myocytes, while dividing HL-1 cardiomyocytes exhibited mainly tyrosinated and acetylated $\alpha$-tubulins; 2) microtubules in adult ventricular myocytes were much more resistant to nocodazole treatment than microtubules in HL-1 cells; however, 3) Glu- $\alpha$-tubulin containing microtubules were more resistant to nocodazole treatment in HL-1 cardiomyocytes than in ventricular myocytes; 4) endogenous activation of the cAMP pathway disrupted the most labile microtubules in HL-1 cardiomyocytes but had no effect on the microtubule network in ventricular myocytes; finally, 5) intracellular $\mathrm{Ca}^{2+}$ accumulation did not modify microtubule stability in ventricular myocytes but reduced the number of $\alpha$-tubulin filaments in HL-1 cells. Altogether, our data demonstrate the unique stability of the microtubule network in adult cardiac myocytes. We speculate that microtubule stability is required to support cellular integrity during cardiac contraction.

The cellular distribution of microtubules in isolated ventricular myocytes was consistent with previous observations in isolated myocytes and whole hearts [16, 33-35]. Selective post-translational modifications of $\alpha$-tubulin were demonstrated in adult ventricular cardiac myocytes. The native, tyrosinated $\alpha$-tubulin, as well as the modified, detyrosinated Glu- $\alpha$-tubulin were abundant and homogeneously distributed within the microtubule network. These isoforms did not segregate in different microtubules (data not shown).

$\Delta_{2}$ - $\alpha$-tubulin was a rare modification of $\alpha$-tubulin, mostly localized within, or in close vicinity to, the microtubule organizing center. Recently, we and others found that $\Delta_{2}-\alpha-$ tubulin subcellular distribution (i.e. soluble vs. polymerized) was severely modified during cardiac hypertrophy and heart failure [12, 22]. 
Acetylated $\alpha$-tubulin was only observed in a very small subset of myocytes. Most adult ventricular myocytes did not harbor this modification. For a comparison, acetylated $\alpha-$ tubulin was an abundant modification of $\alpha$-tubulin in HL-1 cardiomyocytes (this study) and in neonatal myocytes [16]. The possibility exists that a selective depolymerization of acetylated $\alpha$-tubulin containing microtubules might be a consequence of the isolation procedure, since tubulin labeling is lacking in slightly damaged myocytes [35]. However, double labeling experiments demonstrated that total $\alpha$-tubulin staining was normal in cells lacking acetylated $\alpha$-tubulin (data not shown). In addition, acetylated $\alpha$-tubulin labeling was dim in sections from whole adult hearts [16]. These data suggest that tubulin acetyltransferase/acetylase ratio might be low in adult ventricular myocytes, in comparison to immature myocytes. Indeed, acetyltransferase activity is high in early Xenopus embryos, and decreases as cell division slows down [36].

The depolymerizing effect of nocodazole was more efficient in HL-1 cardiomyocytes (this study) and neonatal myocytes [18] than in adult ventricular myocytes. The overall stabilization of the microtubules network can be viewed as a developmental change required to counteract stretch-induced forces occurring during twitches in the adult heart. Microtubule stability might also support other functions in adult myocytes. For instance, chemical depolymerization of the tubulin network was found to impair cellular spreading and remodeling in cultured adult myocytes, but not in neonatal myocytes [37]. Interestingly, Glu$\alpha$-tubulin containing microtubules were more resistant to depolymerization in neonatal myocytes [18], as well as in HL-1 cardiomyocytes. In the latter cells, Glu- $\alpha$-tubulin containing microtubules resisted the depolymerizing effect of nocodazole (Fig. 8). In contrast, Glu- $\alpha$-tubulin containing microtubules in adult myocytes were not any more resistant to chemical depolymerization than the tubulin polymers (Fig. 3), suggesting that microtubules behave as a homogenous population in this preparation. This observation is consistent with 
what was found in other cell types, where tubulin detyrosination is not the primary cause of microtubule stabilization [9, 16-18]. Nevertheless, Glu- $\alpha$-tubulin is likely to support specific cell functions in adult myocytes. As previously shown in fibroblasts where it organizes vimentin intermediate filaments through a kinesin-dependent cross-linking [19, 20], Glu- $\alpha-$ tubulin might also be a privileged microtubular partner to interact with desmin intermediate filaments in myocytes, although to a lesser extent. Glu- $\alpha$-tubulin is significantly modified during cardiac hypertrophy and failure $[12,22]$. In neonatal myocytes, the stable, Glu- $\alpha-$ tubulin containing microtubules were found sufficient to support normal beating rates [9]. However, Glu- $\alpha$-tubulin per se was not responsible for this characteristic, since injection of an anti Glu- $\alpha$-tubulin antibody into neonatal myocytes did not impair the beating rate [9].

Beta-adrenergic receptor activation (using isoprenaline), $\mathrm{G}_{\mathrm{s}}$ protein activation (using cholera toxin) or direct activation of adenylyl cyclase (using L858051) all concur to stimulate cAMP production and elevate cAMP concentration in isolated adult rat ventricular myocytes (see e.g. [38] for a review). The microtubule network of adult myocytes was not modified by activation of the cAMP pathway. However, in neonatal cardiac myocytes, activation of the cAMP pathway was found to induce microtubule breakdown [26]. These results suggest that the effect of cAMP-dependent protein kinase on tubulin dynamics, which involves phosphorylation of the microtubule associated protein 2 (MAP2 [24]), is strong in dividing cardiac myocytes and blunted in differentiated myocytes. Accordingly, MAP2 was found to be localized in Z-bands, and not in microtubules in adult cardiac myocytes [34].

The microtubule network of adult myocytes was not modified by an elevation of intracellular $\mathrm{Ca}^{2+}$ induced by either caffeine or thapsigargin, known to activate $\mathrm{Ca}^{2+}$ release or inhibit $\mathrm{Ca}^{2+}$ uptake by the sarcoplasmic reticulum, respectively (see [39] for a review). In contrast, the $\mathrm{Ca}^{2+}$ ionophore A23187 disrupted microtubules in HL-1 cardiomyocytes. Furthermore, intracellular $\mathrm{Ca}^{2+}$ accumulation was found to induce microtubule breakdown in 
neonatal cardiac myocytes $[18,26]$. Thus, it is tempting to speculate that cardiac microtubules become more resistant to intracellular $\mathrm{Ca}^{2+}$ during development. This change might be related to changes in the expression of calmodulin-dependent protein kinase isoforms during cardiac development [40]. A change in the expression of another $\mathrm{Ca}^{2+}$ regulated protein, $\mathrm{S} 100 \mathrm{~B}$, an inhibitor of microtubules polymerization, might also be involved in cardiac microtubule stability [41]. Indeed, S100B is associated with microtubules in dividing myoblasts, but not in differentiated cells [42]. $\mathrm{Ca}^{2+}$ has been shown to accelerate depolymerization of microtubules in reperfused myocardium after a brief period of ischemia [43]. We speculate that $\mathrm{Ca}^{2+}$ per se cannot be the relevant signal involved in this pathology and/or that another ischemic product might potentiate or facilitate the effect of $\mathrm{Ca}^{2+}$ on microtubules.

Adult ventricular myocytes exhibit a unique pattern of $\alpha$-tubulin modifications and a stable microtubule network, unlike HL-1 and neonatal cardiomyocytes. As discussed above, developmental changes might account for these differences. However, we cannot rule out the possibility that part of the differences shown are due to changes in the microtubule organization taking place at the onset of the culture procedure and/or during passaging of the cells [35, 44]. Nevertheless, our present results suggest that changes in the microtubule network during heart failure are likely to have profound consequences on cardiac performances.

\section{Acknowledgements}

We thank Patrick Lechêne for his excellent technical assistance, Florence Lefebvre for cardiac myocytes isolations, and Valérie Nicolas from the Service Commun d'Imagerie Cellulaire of the Institut de Signalisation et Innovation Thérapeutique (IFR-75 ISIT) for help with the experiments using the confocal microscope. We thank Dr. L. Paturle-Lafanechère and Dr. P. Denoulet for generous gifts of primary antibodies and Dr. Anne Drechou for helpful 
discussions. S. B. was supported by the Fondation pour la Recherche Médicale (F.R.M) and the Société de Secours des Amis de la Science. 


\section{References}

1. Brinkley W: Microtubules: a brief historical perspective. J Struct Biol 118: 84-86, 1997

2. Rieder CL, Khodjakov A: Mitosis and checkpoints that control progression through mitosis in vertebrate somatic cells. Prog Cell Cycle Res 3: 301-312, 1997

3. Sheetz MP: Motor and cargo interactions. Eur J Biochem 262: 19-25, 1999

4. Mitchison T, Kirschner M: Microtubule assembly nucleated by isolated centrosomes. Nature 312: 232-237, 1984

5. Nogales E: A structural view of microtubule dynamics. Cell Mol Life Sci 56: 133-142, 1999

6. McIntosh JR, Hering GE: Spindle fiber action and chromosome movement. Ann Rev Cell Biol 7: 403-426, 1991

7. Wilson L, Jordan MA: Microtubule dynamics: taking aim at a moving target. Chem Biol 2: $569-573,1995$

8. Tagawa H, Koide M, Sato H, Zile MR, Carabello BA, Cooper G $4^{\text {th. }}$. Cytoskeletal role in the transition from compensated to decompensated hypertrophy during adult canine left ventricular pressure overloading. Circ Res 82: 751-761, 1998

9. Webster DR, Patrick DL: Beating rate of isolated neonatal cardiomyocytes is regulated by the stable microtubules subset. Am J Physiol Heart Circ Physiol 278: H1653-H1661, 2000

10. Tsutsui H, Ishihara K, Cooper $\mathrm{G} 4^{\text {th }}$ : Cytoskeletal role in the contractile dysfunction of hypertrophied myocardium. Science 260: 682-687, 1993

11. Hein S, Kostin S, Heling A, Maeno Y, Schaper J: The role of the cytoskeleton in heart failure. Cardiovasc Res 45: 273-278, 2000 
12. Belmadani S, Poüs C, Ventura-Clapier R, Fischmeister R, Méry PF: Post-translational modifications of cardiac tubulin during chronic heart failure in the rat. Mol Cell Biochem 237: 39-46, 2002

13. Howarth FC, Calaghan SC, Boyett MR, White E: Effect of the microtubule polymerizing agent taxol on contraction, $\mathrm{Ca}^{2+}$ transient and $\mathrm{L}$-type $\mathrm{Ca}^{2+}$ current in rat ventricular myocytes. J Physiol 516: 409-419, 1999

14. Gomez AM, Kerfant BG, Vassort G: Microtubule disruption modulates $\mathrm{Ca}^{2+}$ signaling in rat cardiac myocytes. Circ Res 86: 30-36, 2000

15. Calaghan SC, Le Guennec JY, White E: Modulation of $\mathrm{Ca}^{2+}$ signaling by microtubule disruption in rat ventricular myocytes and its dependence on the ruptured patch-clamp configuration. Circ Res 88: E32-E37, 2001

16. Webster DR: Regulation of post-translationally modified microtubule populations during neonatal cardiac development. J Mol Cell Cardiol 29: 1747-1761, 1997

17. Rosenbaum J: Cytoskeleton: functions for tubulin modifications at last. Curr Biol 10: R801-R803, 2000

18. Webster DR: Neonatal rat cardiomyocytes possess a large population of stable microtubules that is enriched in post-translationally modified subunits. J Mol Cell Cardiol 29:2813-2824, 1997

19. Gurland G, Gundersen GG: Stable, detyrosinated microtubules function to localize vimentin intermediate filaments in fibroblasts. J Cell Biol 131: 1275-1290, 1995

20. Kreitzer G, Liao G, Gundersen GG: Detyrosination of tubulin regulates the interaction of intermediate filaments with microtubules in vivo via a kinesin-dependent mechanism. Mol Biol Cell 10: 1105-1118, 1999 
21. Paturle-Lafanechère L, Manier $M$, Trigault N, Pirollet F, Mazarguil H, Job D: Accumulation of $\Delta_{2}$-tubulin, a major tubulin variant that cannot be tyrosinated, in neuronal tissues and in stable microtubule assemblies. J Cell Sci 107: 1529-1543, 1994

22. Sato H, Nagai T, Kuppuswamy D, Narishige T, Koide M, Menick DR, Cooper G $4^{\text {th: }}$ Microtubule stabilization in pressure overload cardiac hypertrophy. J Cell Biol 139: 963973,1997

23. Gundersen GG, Cook TA: Microtubules and signal transduction. Curr Opin Cell Biol 11: 81-94, 1999

24. Diviani D, Scott JD: AKAP signaling complexes at the cytoskeleton. J Cell Sci 114: $1431-1437,2001$

25. Keith C, DiPaola M, Maxfield FR, Shelanski ML: Microinjection of $\mathrm{Ca}^{++}$-calmodulin causes a localized depolymerization of microtubules. J Cell Biol 97: 1918-1924, 1983

26. Hori M, Sato H, Kitakaze M, Iwai K, Takeda H, Inoue M, Kamada T: $\beta$-adrenergic stimulation disassembles microtubules in neonatal rat cultured cardiomyocytes through intracellular $\mathrm{Ca}^{2+}$ overload. Circ Res 75: 324-334, 1994

27. Cau J, Faure S, Comps M, Delsert C, Morin N: A novel p21-activated kinase binds the actin and microtubule networks and induces microtubule stabilization. J Cell Biol 155: 1029-1042, 2001

28. Palazzo AF, Cook TA, Alberts AS, Gundersen GG: mDia mediates Rho-regulated formation and orientation of stable microtubules. Nat Cell Biol 3: 723-729, 2001

29. Roychowdhury S, Rasenick MM: G protein $\beta_{1} \gamma_{2}$ subunits promote microtubule assembly. J Biol Chem 272: 31576-31581, 1997

30. Roychodhury S, Panda D, Wilson L, Rasenick MM: J Biol Chem 274: 13485-13490, 1999 
31. Claycomb WC, Lanson NA Jr, Stallworth BS, Egeland DB, Delcarpio JB, Bahinski A, Izzo NJ Jr: HL-1 cells: a cardiac muscle cell line that contracts and retains phenotypic characteristics of the adult cardiomyocyte. Proc Natl Acad Sci USA 95: 2979-2984, 1998

32. Abi-Gerges N, Eschenhagen T, Hove-Madsen L, Fischmeister R, Méry PF: Methylene blue is a muscarinic antagonist in cardiac myocytes. Mol Pharmacol 52: 482-490, 1997

33. Samuel JL, Schwartz K, Lompre AM, Delcayre C, Marotte F, Swynghedauw B, Rappaport L: Immunological quantitation and localization of tubulin in adult rat heart isolated myocytes. Eur J Cell Biol 31: 99-106, 1983

34. Zernig G, Wiche G: Morphological integrity of single adult cardiac myocytes isolated by collagenase treatment: immunolocalization of tubulin, microtubule-associated proteins 1 and 2, plectin, vimentin, and vinculin. Eur J Cell Biol 38: 113-122, 1985

35. Guo JX, Jacobson SL, Brown DL: Rearrangement of tubulin, actin, and myosin in cultured ventricular cardiomyocytes of the adult rat. Cell Motil Cytoskeleton 6: 291-304, 1986

36. Chu DT, Klymkowsky MW: The appearance of acetylated alpha-tubulin during early development and cellular differentiation in Xenopus. Dev Biol 136: 104-117, 1989

37. Rothen-Rutishauser BM, Ehler E, Perriard E, Messerli JM, Perriard JC: Different behaviour of the non-sarcomeric cytoskeleton in neonatal and adult rat cardiomyocytes. $\mathbf{J}$ Mol Cell Cardiol 30: 19-31, 1998

38. Defer N, Best-Belpomme M, Hanoune J: Tissue specificity and physiological relevance of various isoforms of adenylyl cyclase. Am J Physiol Renal Physiol 279: F400-F416, 2000

39. Bers DM: Cardiac excitation-contraction coupling. Nature 2002;415: 198-205. 
40. Hagemann D, Hoch B, Krause EG, Karczewski P: Developmental changes in isoform expression of $\mathrm{Ca}^{2+} /$ calmodulin-dependent protein kinase II delta-subunit in rat heart. $\mathbf{J}$ Cell Biochem 74: 202-210, 1999

41. Garbuglia M, Verzini M, Sorci G, Bianchi R, Giambanco I, Agneletti AL, Donato R: The calcium-modulated proteins, S100A1 and S100B, as potential regulators of the dynamics of type III intermediate filaments. Braz J Med Biol Res 32: 1177-1185, 1999

42. Sorci G, Bianchi R, Giambanco I, Rambotti MG, Donato R: Replicating myoblasts and fused myotubes express the calcium-regulated proteins S100A1 and S100B. Cell Calcium 25: 93-106, 1999

43. Sato H, Hori M, Kitakaze M, Iwai K, Takashima S, Kurihara H, Inoue M, Kamada T: Reperfusion after brief ischemia disrupts the microtubule network in canine hearts. Circ Res 72: 361-375, 1993

44. Rappaport L, Samuel JL: Microtubules in cardiac myocytes. Int Rev Cytol 113: 101-143, 1988 


\section{Figure Legends}

Fig. 1. Double indirect immunofluorescence staining of $\alpha$-and $\beta$-tubulin in ventricular myocytes isolated from rat hearts. (A) and (B), distribution and organization of tubulins in intact cardiac myocytes assessed by confocal microscopy. 16 pictures were taken in the Zaxis, with a step of $0.9 \mu \mathrm{m}$. Representative examples are labeled 1 (bottom of the myocyte) to 15 (top). (C) After image thresholding to keep only the specific signal, the overall immunofluorescence intensity of $\alpha$-tubulin (squares) and $\beta$-tubulin stainings (circles) in each of the 16 confocal sections was quantified and normalized to the intensity value of the brightest slice (same experiment as in A et B). The scale bar shown in (A, top) applies to all images.

Fig. 2. Post-translational modifications of $\alpha$-tubulin in isolated ventricular myocytes. Indirect immunofluorescence staining of myocytes with anti $\alpha$-tubulin (A), anti tyrosinated $\alpha$-tubulin (B), anti Glu- $\alpha$-tubulin (C), anti $\Delta_{2}$ - $\alpha$-tubulin (D), anti polyglutamylated tubulin (E), anti acetylated $\alpha$-tubulin $(\mathrm{F})$. Pictures are $0.9 \mu \mathrm{m}(\mathrm{A}, \mathrm{B}, \mathrm{E}, \mathrm{F})$ or $1 \mu \mathrm{m}(\mathrm{C}, \mathrm{G}, \mathrm{H})$ confocal sections taken at the level of the nuclei. Lack of staining in myocytes incubated with the secondary antibodies alone is shown in $(\mathrm{G})$ and $(\mathrm{H})$ with phase contrast (Nomarski) images of the myocytes shown in the right panels. The scale bar shown in (A) applies to all images.

Fig. 3. Effect of nocodazole on tubulin distribution in isolated ventricular myocytes. Myocytes were incubated without (A) or with nocodazole: $1 \mathrm{nM}$ during $1 \mathrm{~h}(\mathrm{~B}) ; 0.1 \mu \mathrm{M}$ during $1 \mathrm{~h}(\mathrm{C})$; or $10 \mu \mathrm{M}$ during $2 \mathrm{~h}(\mathrm{D})$. Myocytes were stained with anti $\alpha$-tubulin (left), anti $\beta$-tubulin (middle), or anti Glu- $\alpha$-tubulin (right). Each picture is a single $0.9 \mu \mathrm{m}$ confocal 
sections taken at the level of the nuclei. Bottom right, an enlargement (x 4.3) of the Glu- $\alpha-$ tubulin staining in the myocyte treated with $10 \mu \mathrm{M}$ nocodazole (area delimited by the white frame). The $10 \mu \mathrm{m}$ scale bar shown in upper left (A) applies to all images unless specified.

Fig. 4. Effect of adenylyl cyclase activation and intracellular $\mathrm{Ca}^{2+}$ accumulation on tubulin distribution in isolated rat ventricular myocytes. Myocytes were incubated under control solution (A, D) or in the presence of $20 \mu \mathrm{M}$ L858051 for $1 \mathrm{~h}(\mathrm{~B}), 10 \mu \mathrm{M}$ isoprenaline for 30 $\min (\mathrm{C}), 10 \mathrm{mM}$ caffeine for $15 \mathrm{~min}(\mathrm{E})$, or $2 \mu \mathrm{M}$ thapsigargin for $10 \mathrm{~min}(\mathrm{~F})$. Myocytes were stained with anti $\alpha$-tubulin (upper panels), or anti Glu- $\alpha$-tubulin (lower panels). Each micrograph is a single $0.9 \mu \mathrm{m}$ confocal section taken at the level of the nuclei. Scale bars represent $10 \mu \mathrm{m}$.

Fig. 5. Double indirect immunofluorescence labeling of $\alpha$-and $\beta$-tubulin in HL-1 cardiomyocytes. The cells were labeled with anti $\alpha$-tubulin (A) and anti $\beta$-tubulin (B). The images were superimposed in (C). (D) 8 pictures were taken in the Z-axis of the cells, with a step of $0.9 \mu \mathrm{m}$. The immunofluorescence intensity of $\alpha$-tubulin (circles) and $\beta$-tubulin stainings (squares) in each of the 8 confocal sections was quantified and normalized to their respective maximal values (same experiment as in A-C). Each immunofluorescence image is a single $0.8 \mu \mathrm{m}$ confocal section taken at the level of the nuclei. Lack of staining in myocytes incubated with the secondary antibodies alone is shown in $(\mathrm{E})$ and $(\mathrm{F})$ upper parts with phase contrast (Nomarski) images of the cell culture shown in the bottom parts. Scale bars represent $20 \mu \mathrm{m}$.

Fig. 6. Post-translational modifications of $\alpha$-tubulin in HL-1 cardiomyocytes. Double immunolabelings with anti $\alpha$-tubulin (left images in A, B, C), anti tyrosinated $\alpha$-tubulin 
(middle image in A), anti Glu- $\alpha$-tubulin (middle image in B), or anti acetylated- $\alpha$-tubulin (middle image in C). Each micrograph is a single $0.8 \mu \mathrm{m}$ confocal section taken at the level of the nuclei. The left and middle images in (A), (B) or (C) are superimposed in the third image on the right of each panel. The scale bars shown on the left images apply to the whole series.

Fig. 7. Effect of nocodazole on tubulin distribution in HL-1 cardiomyocytes. Myocytes were incubated without (A, C, E, G) or with nocodazole $(0.1 \mu \mathrm{M}$ for $1 \mathrm{~h}$ in $\mathrm{B}, \mathrm{D}, \mathrm{F}, \mathrm{H})$. Myocytes were labeled with anti $\beta$-tubulin (A, B), anti $\alpha$-tubulin (C, D), anti acetylated $\alpha$-tubulin (E, F), or anti Glu- $\alpha$-tubulin $(\mathrm{G}, \mathrm{H})$. Each picture is a single $0.8 \mu \mathrm{m}$ confocal section taken at the level of the nuclei. The scale bar shown in (A) applies to all images.

Fig. 8. Effect of adenylyl cyclase activation on tubulin distribution in HL-1 cardiomyocytes. Myocytes were incubated either in the absence (A,C, E, G) or presence of $20 \mu \mathrm{M}$ L858051 (20 min in B, D, F, H). HL-1 cells were labeled with anti $\beta$-tubulin (A, B), or anti $\alpha$-tubulin (C, D), anti acetylated $\alpha$-tubulin $(\mathrm{E}, \mathrm{F})$, or anti Glu- $\alpha$-tubulin $(\mathrm{G}, \mathrm{H})$. Each micrograph is a single $0.8 \mu \mathrm{m}$ confocal section taken at the level of the nuclei. The scale bar shown in (A) applies to all images. 


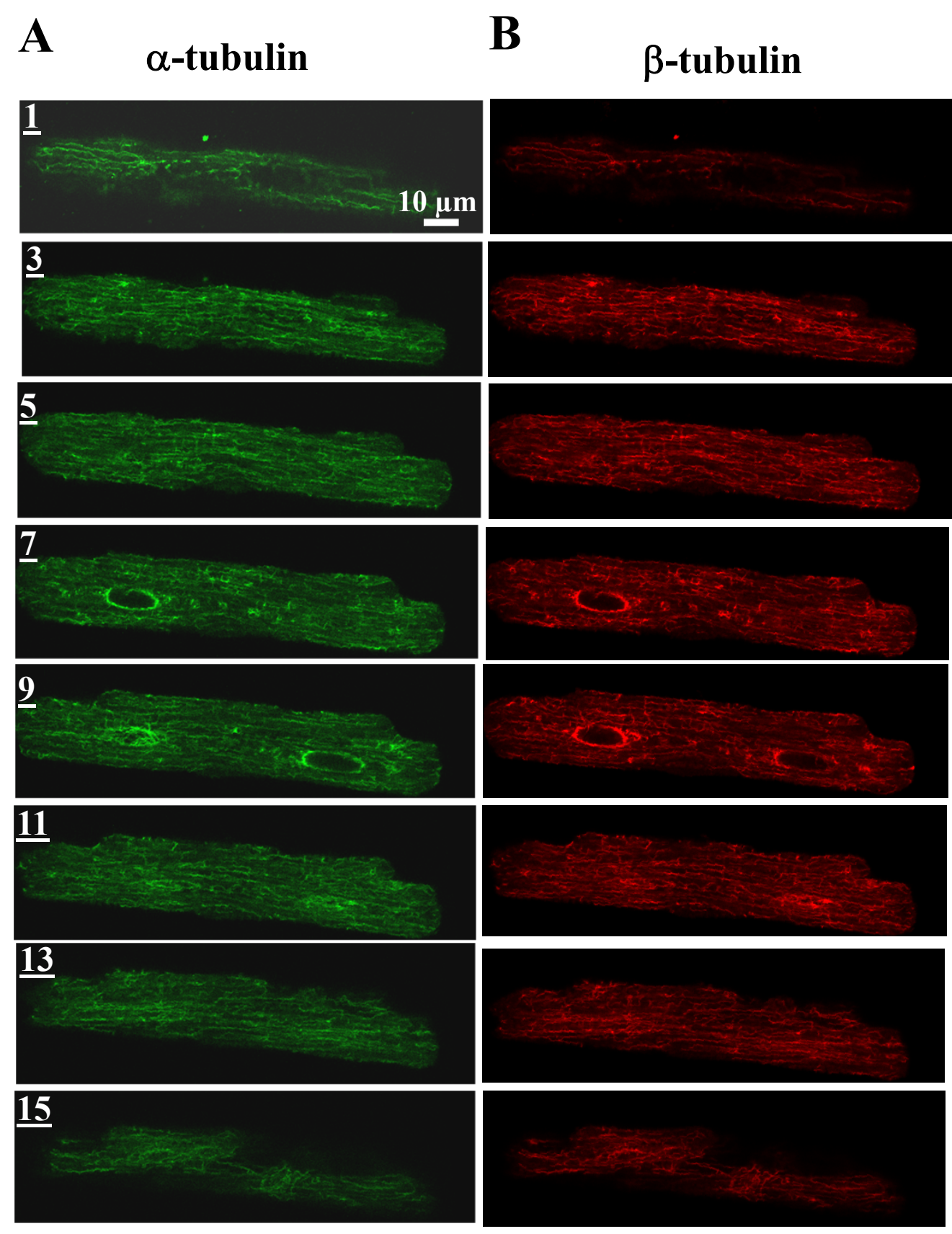

C

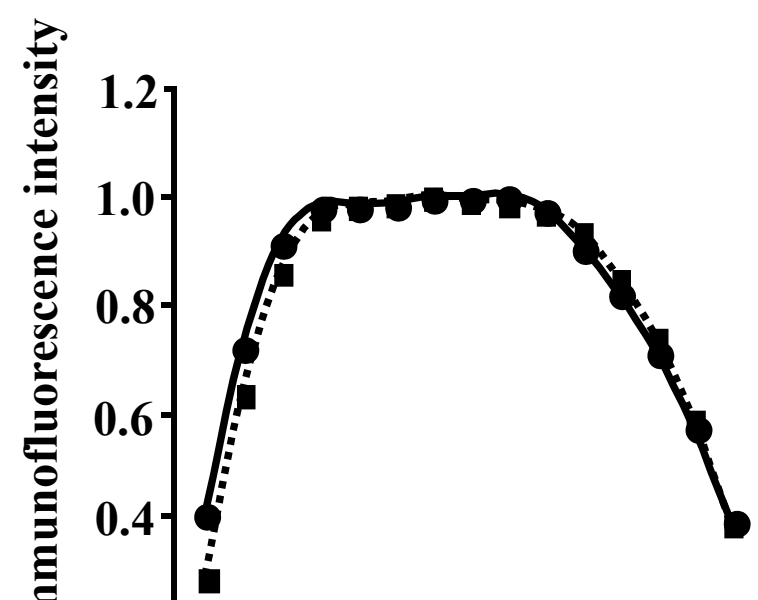

国 0.2 - $\alpha$-tubulin

$\stackrel{0}{\bullet} \beta$-tubulin

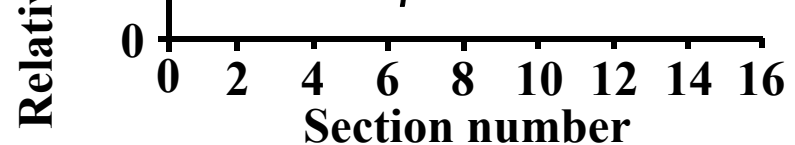

Figure 1 
A

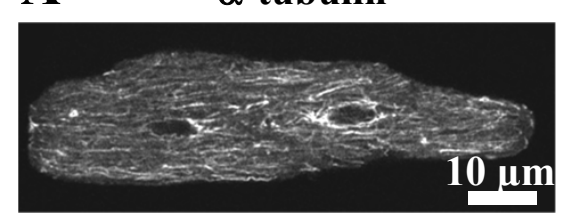

D

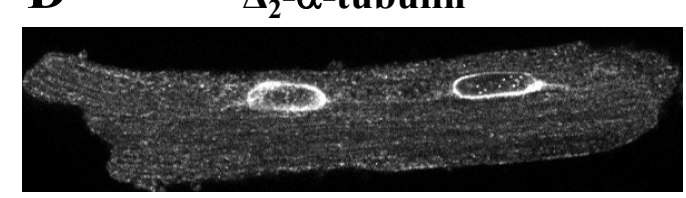

G FITC secondary antibody

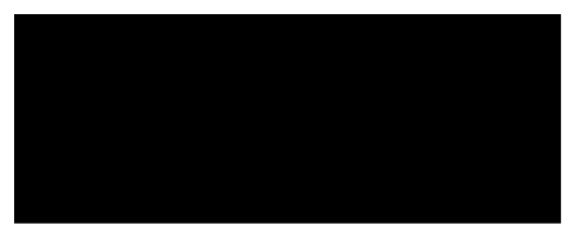

H TRITC secondary antibody

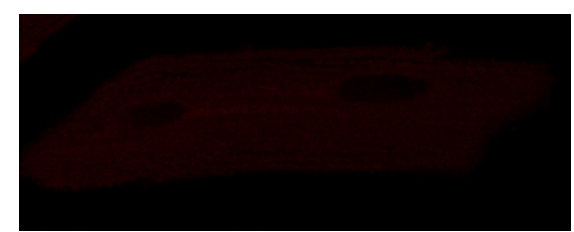

B

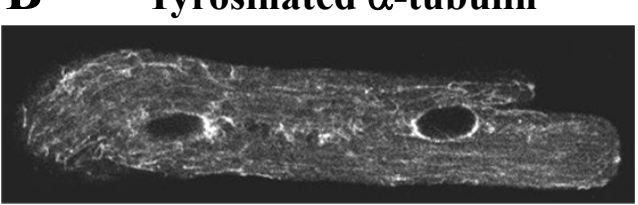

E Polyglutamylated tubulin

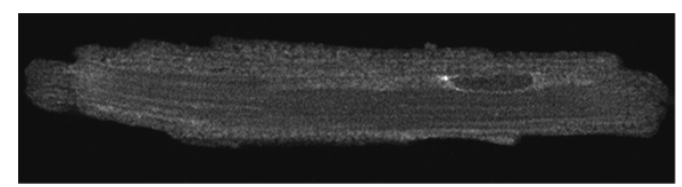

F

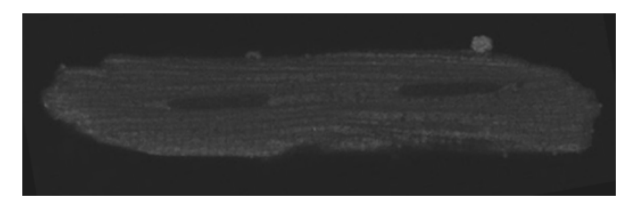

Acetylated $\alpha$-tubulin
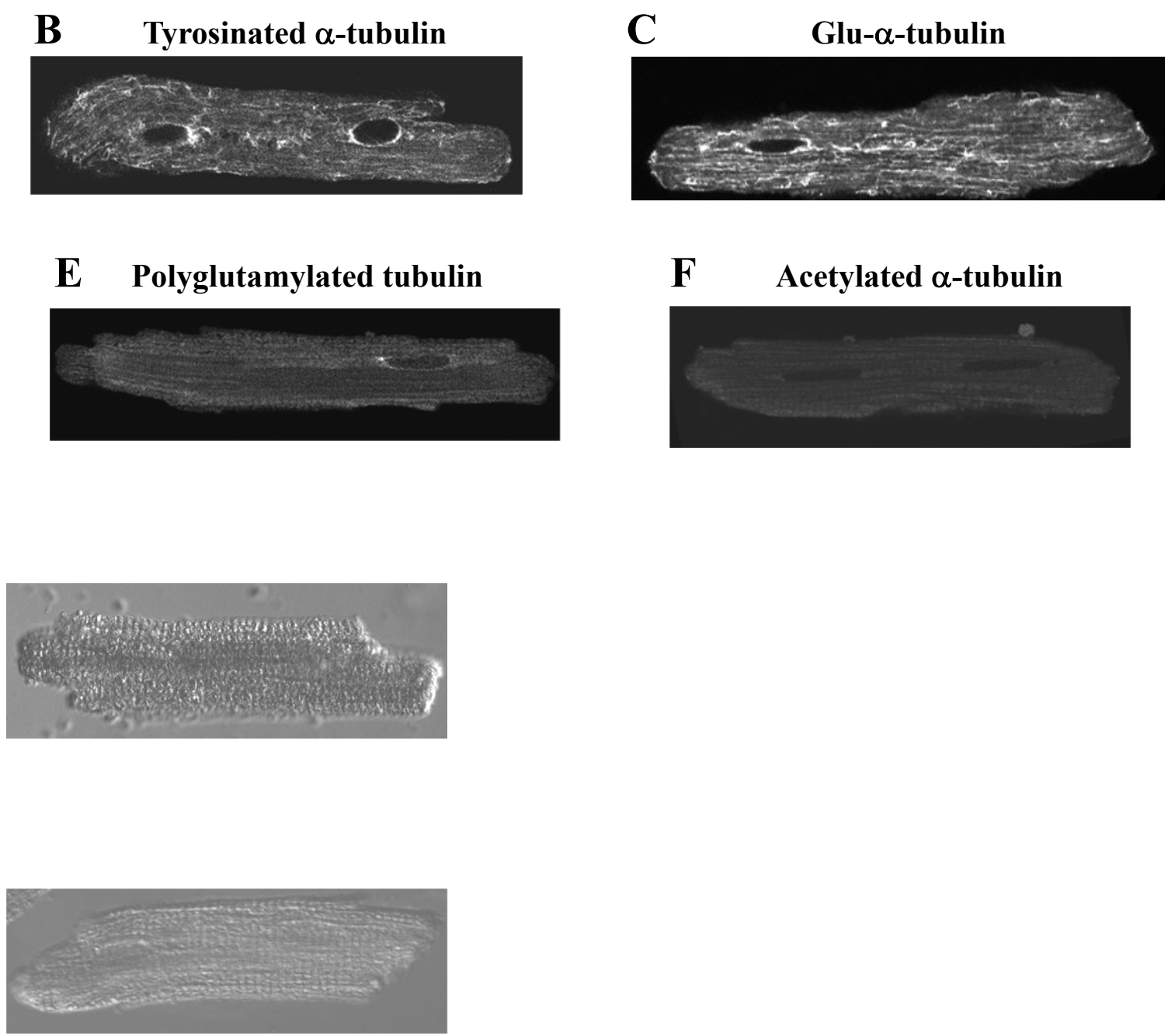

Figure 2 
$\beta$-tubulin

A Control

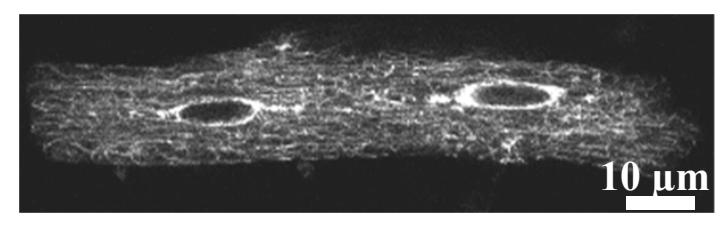

B Nocodazole $(1 \mathrm{nM}, 1 \mathrm{~h})$

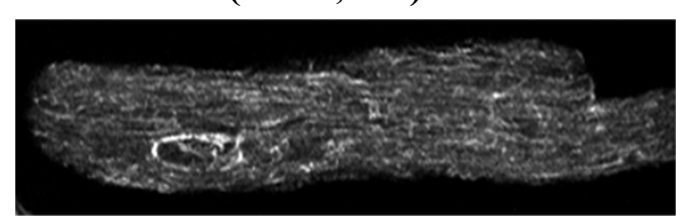

C Nocodazole $(0.1 \mu \mathrm{M}, 1$ h)

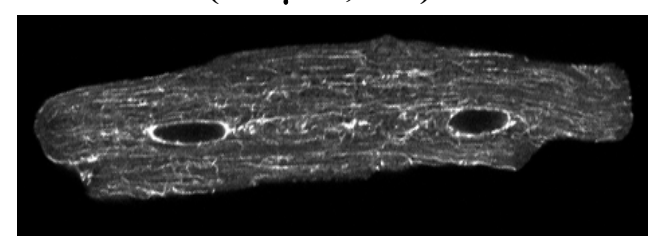

D Nocodazole $(10 \mu \mathrm{M}, 2 \mathrm{~h})$

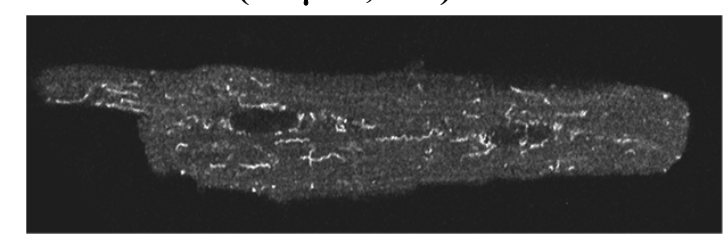

Figure 3 $\alpha$-tubulin
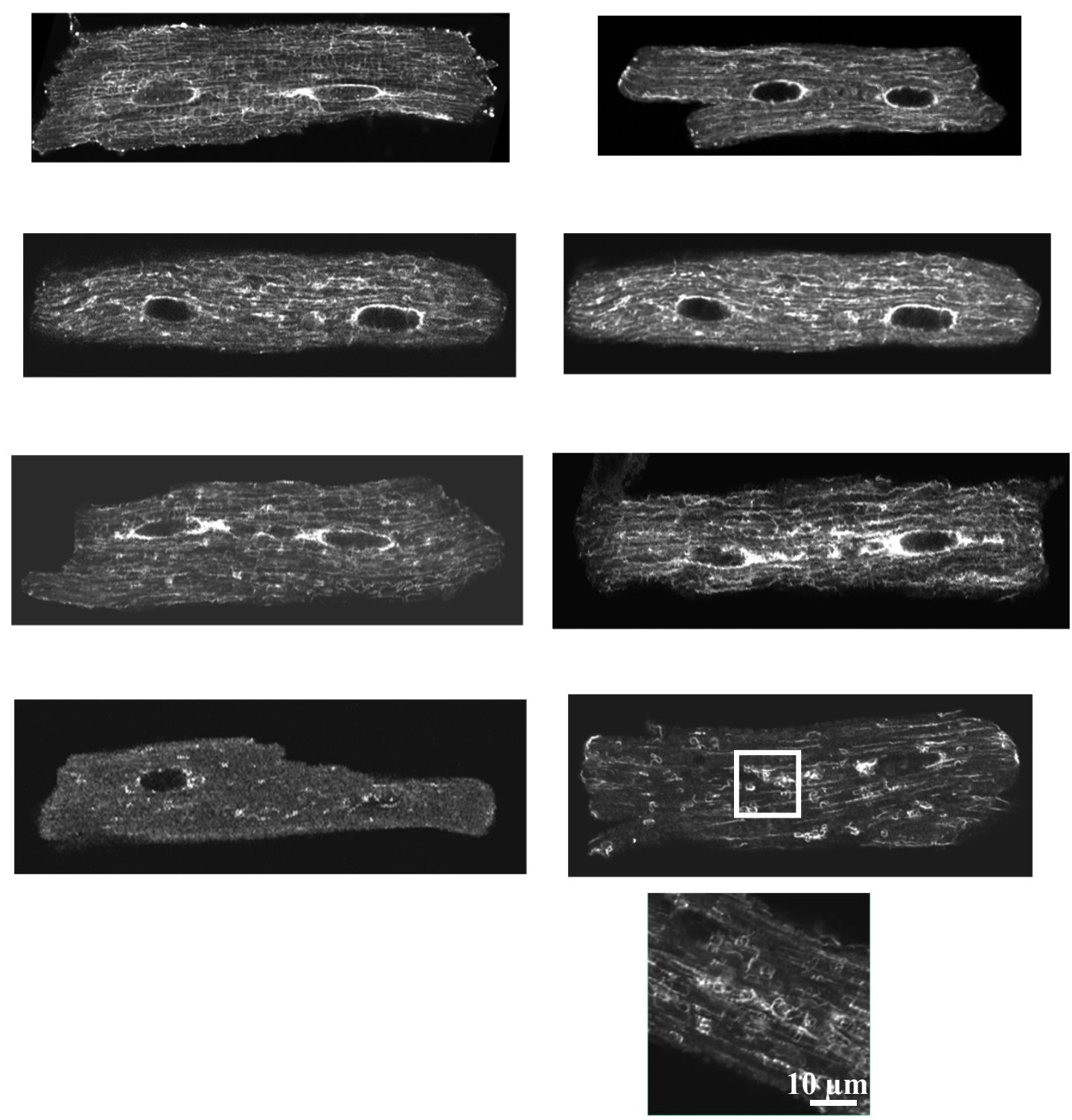


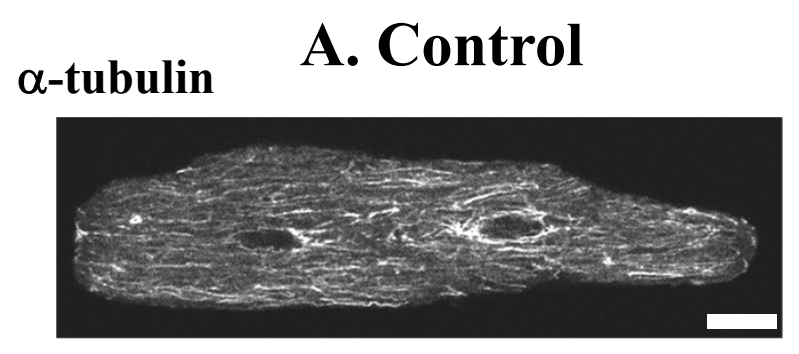

B. $\mathbf{L 8 5 8 0 5 1}$

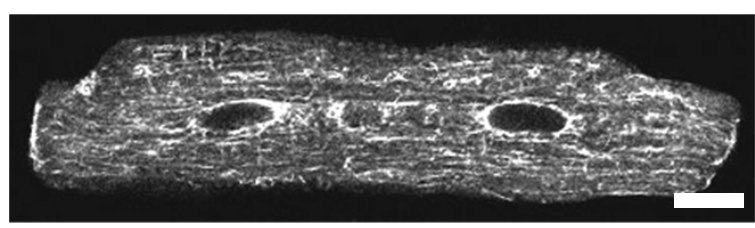

Glu- $\alpha$-tubulin
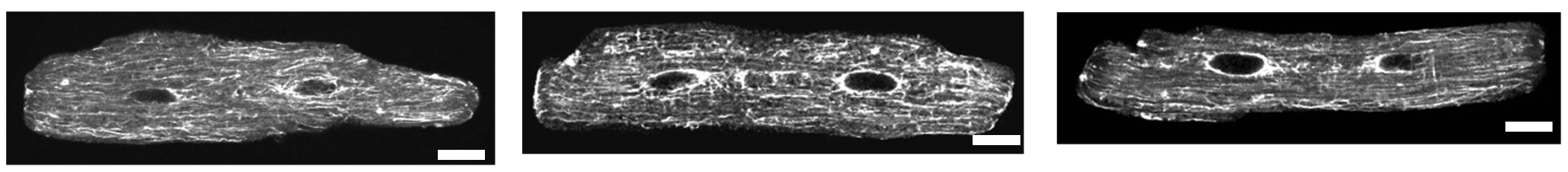

$\alpha$-tubulin

D. Control

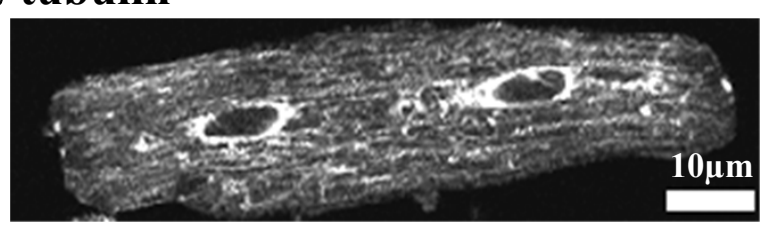

Glu- $\alpha$-tubulin
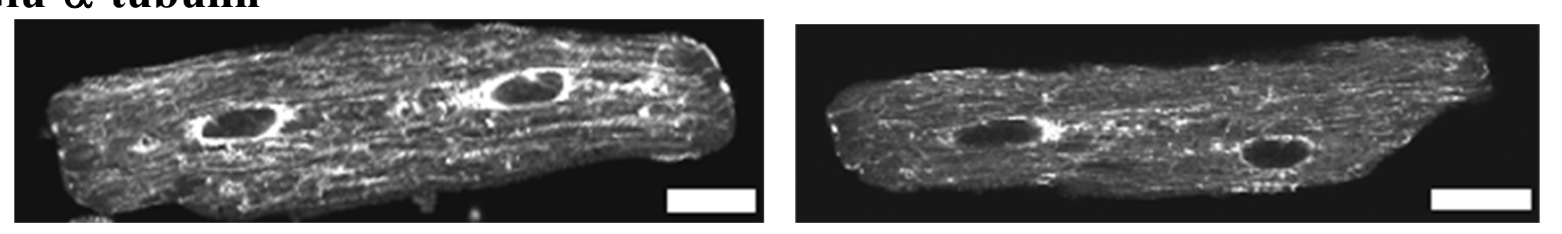

C. Isoprenaline

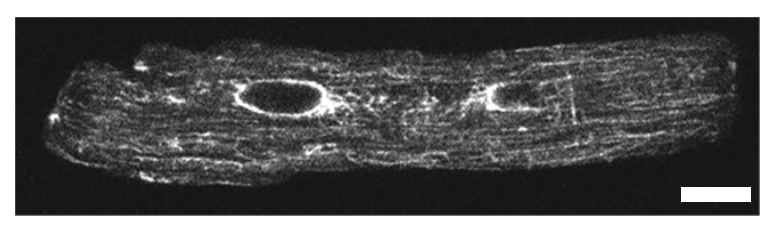

E. Caffeine

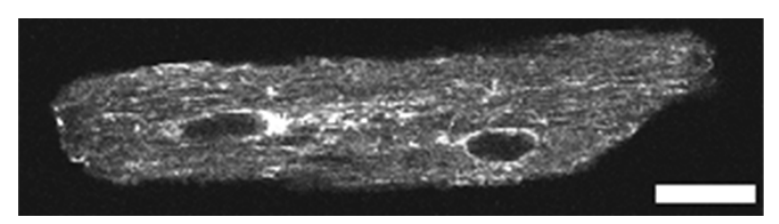

F. Thapsigargin

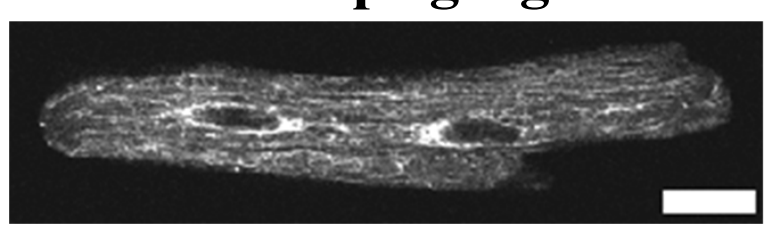

Figure 4

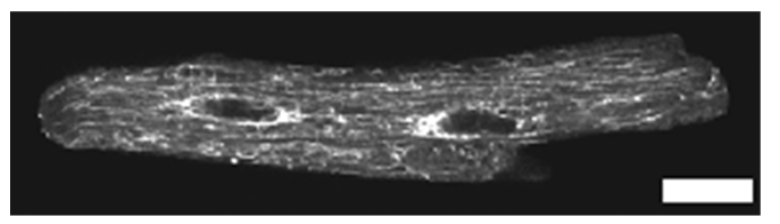



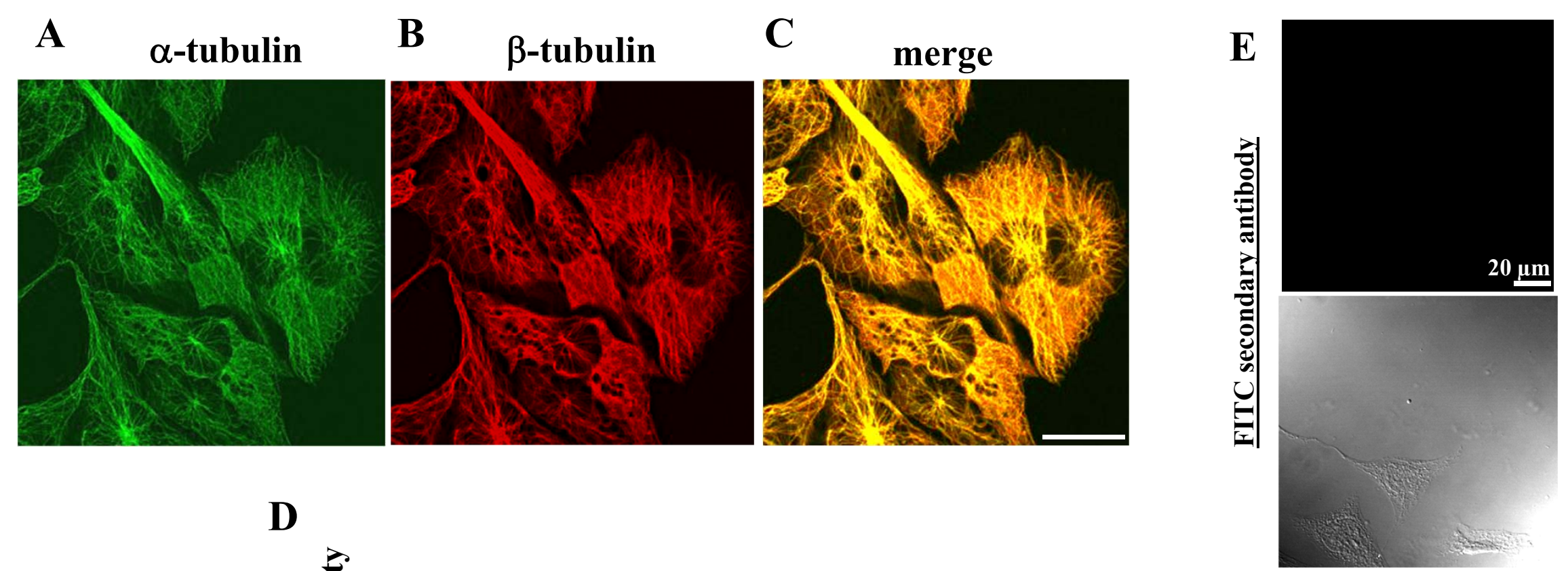

D

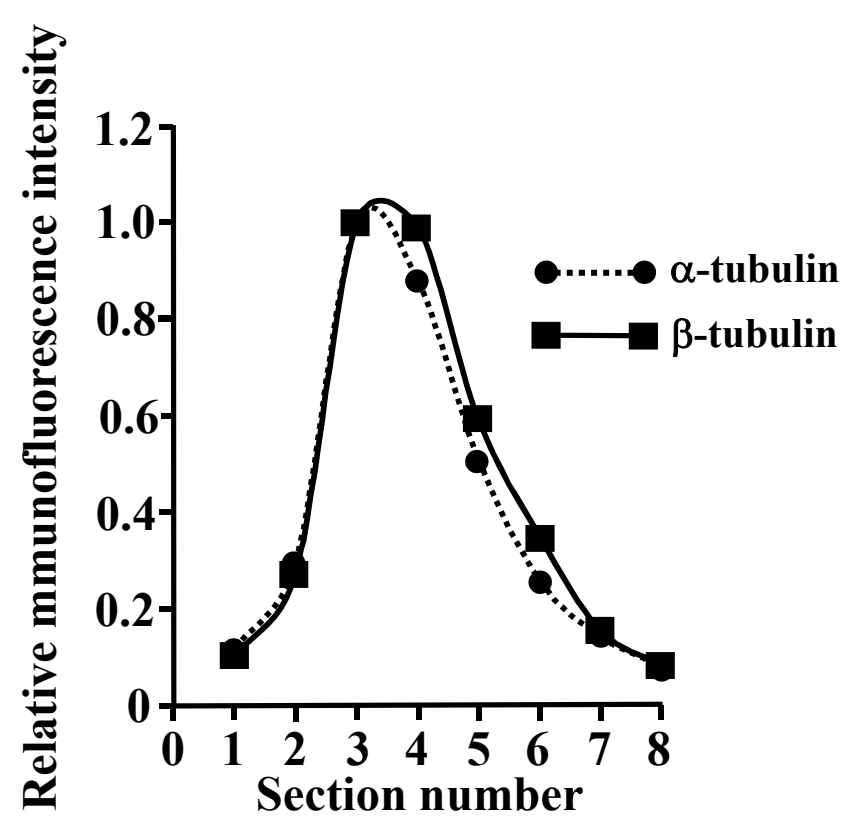

F

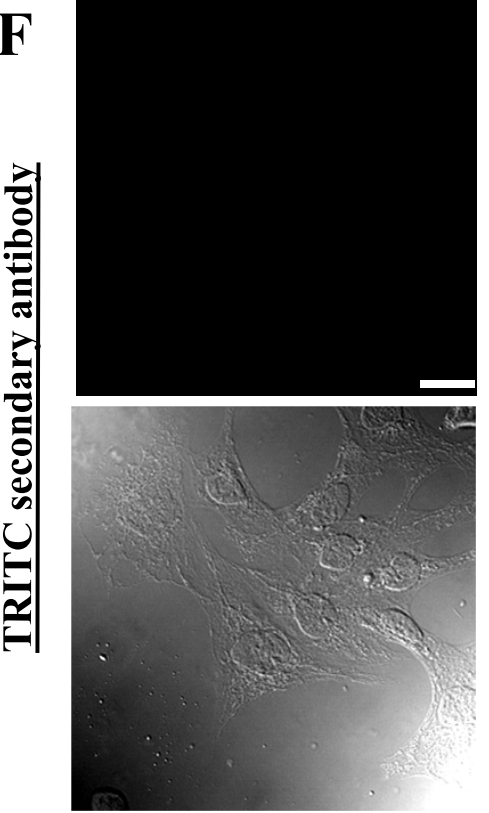

Figure 5 


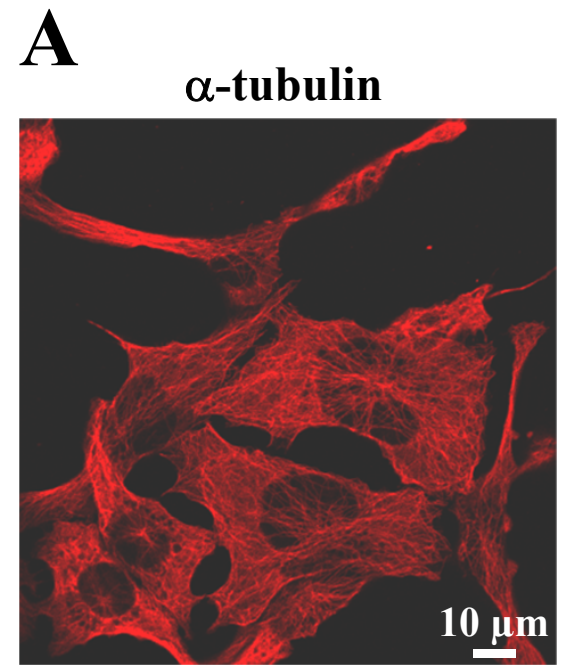

Tyrosinated $\alpha$-tubulin

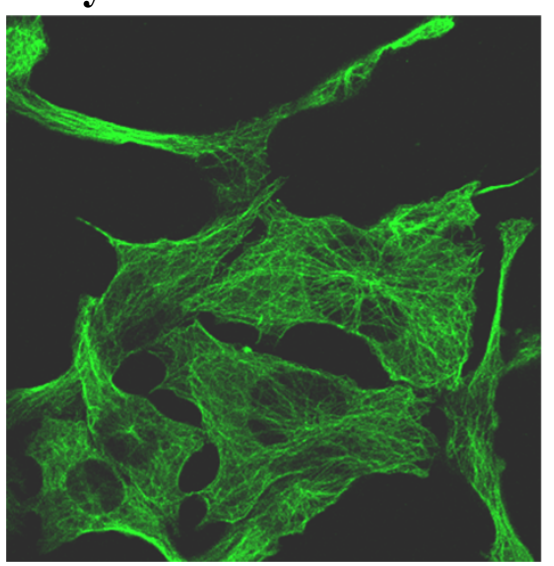

B

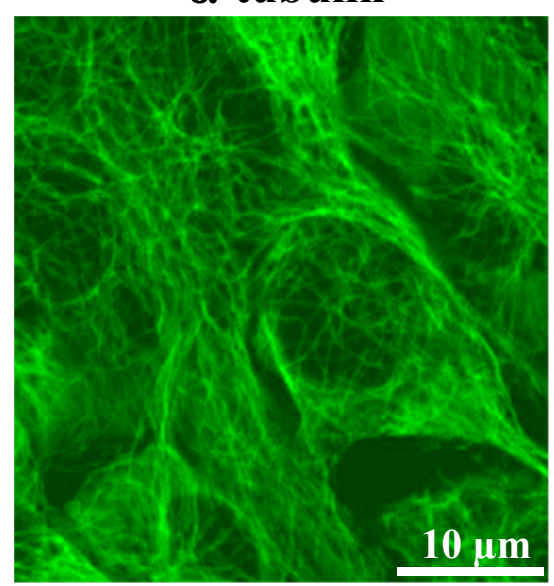

C

$\alpha$-tubulin

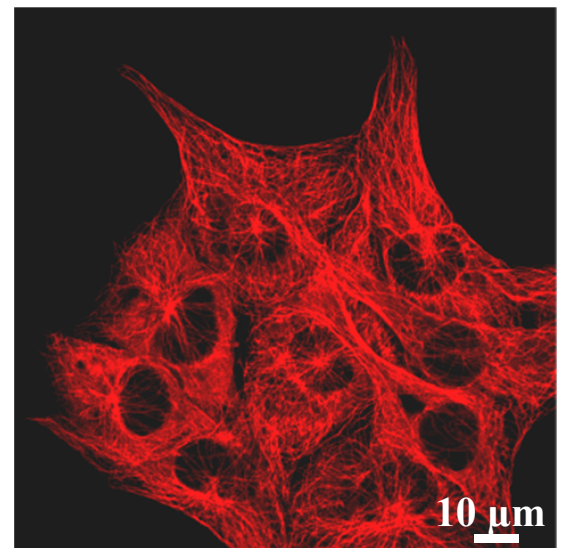

Glu- $\alpha-$ tubulin

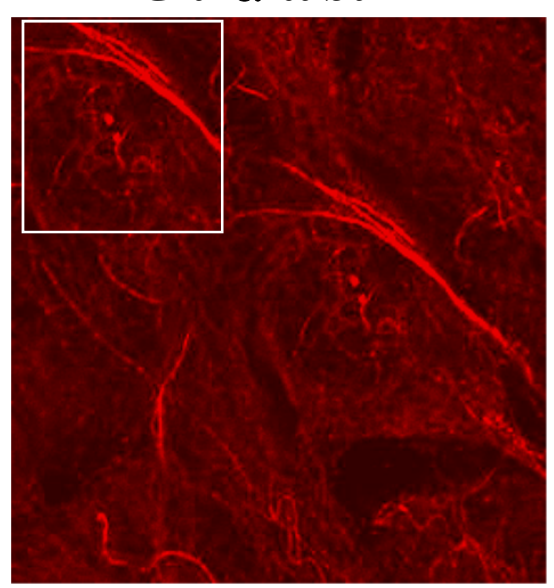

Acetylated $\alpha$-tubulin

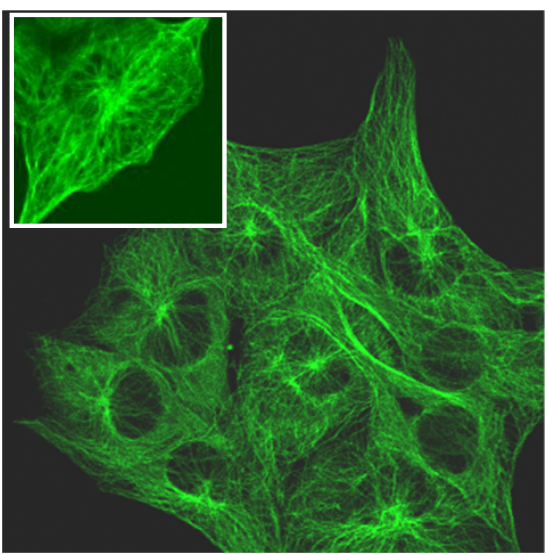

merge

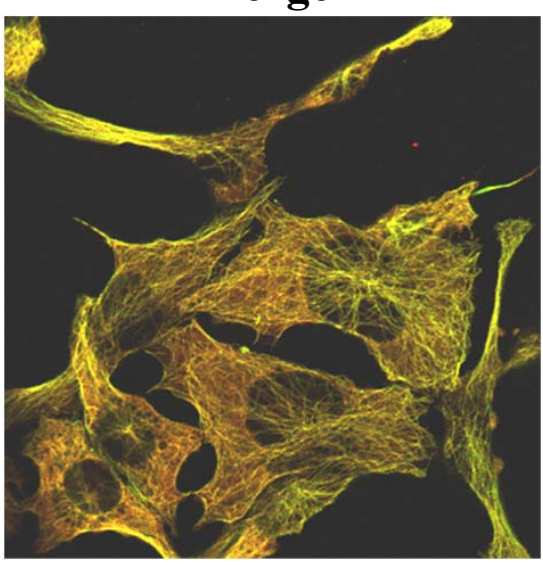

merge

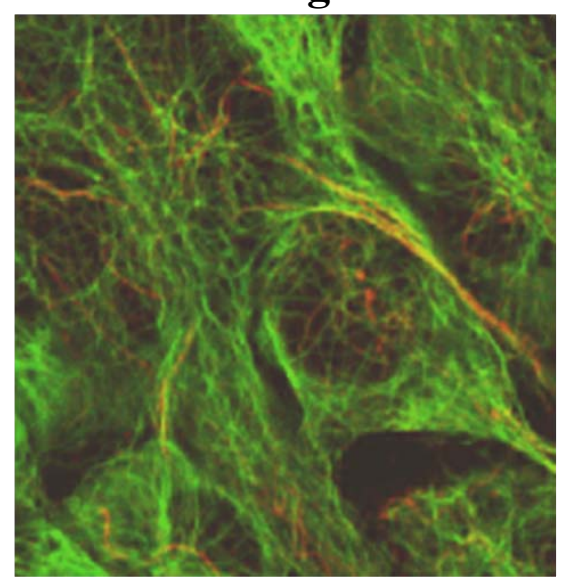

merge

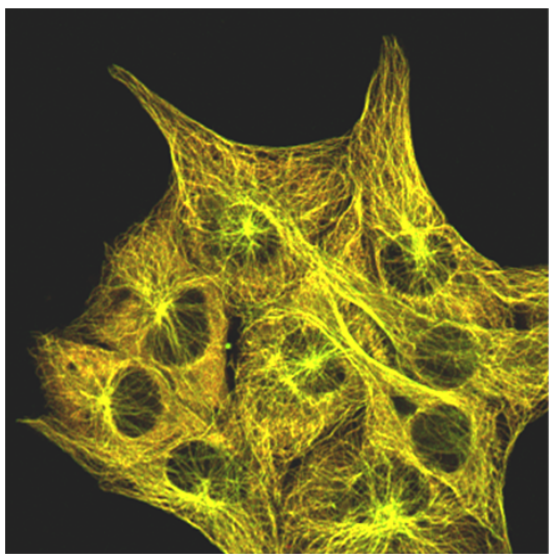

Figure 6 

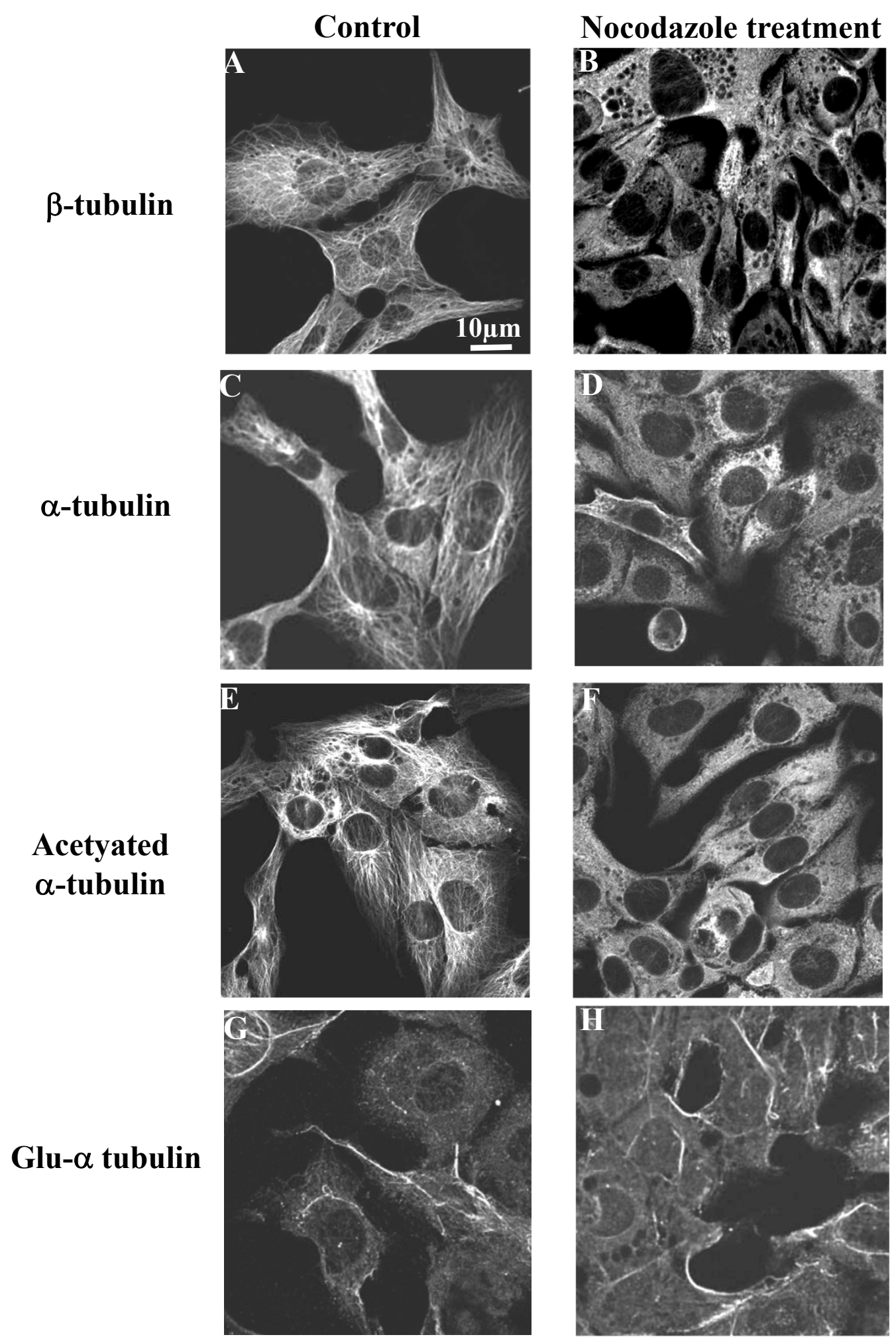

Figure 7 


\section{Control HL-1 cells}

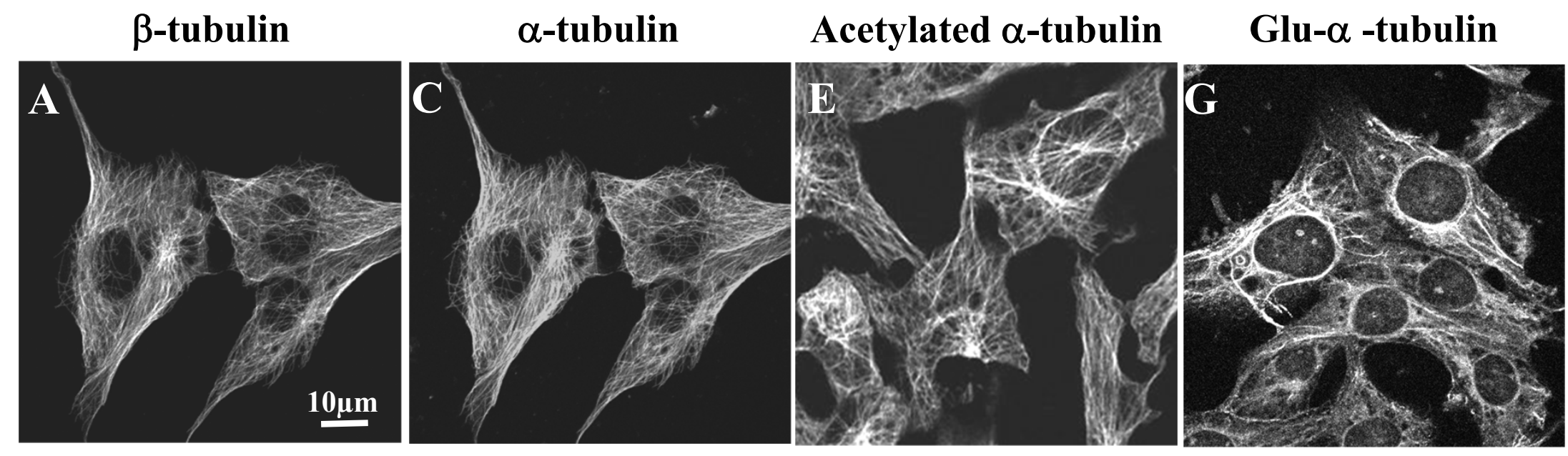

L858051 treated HL-1 cells

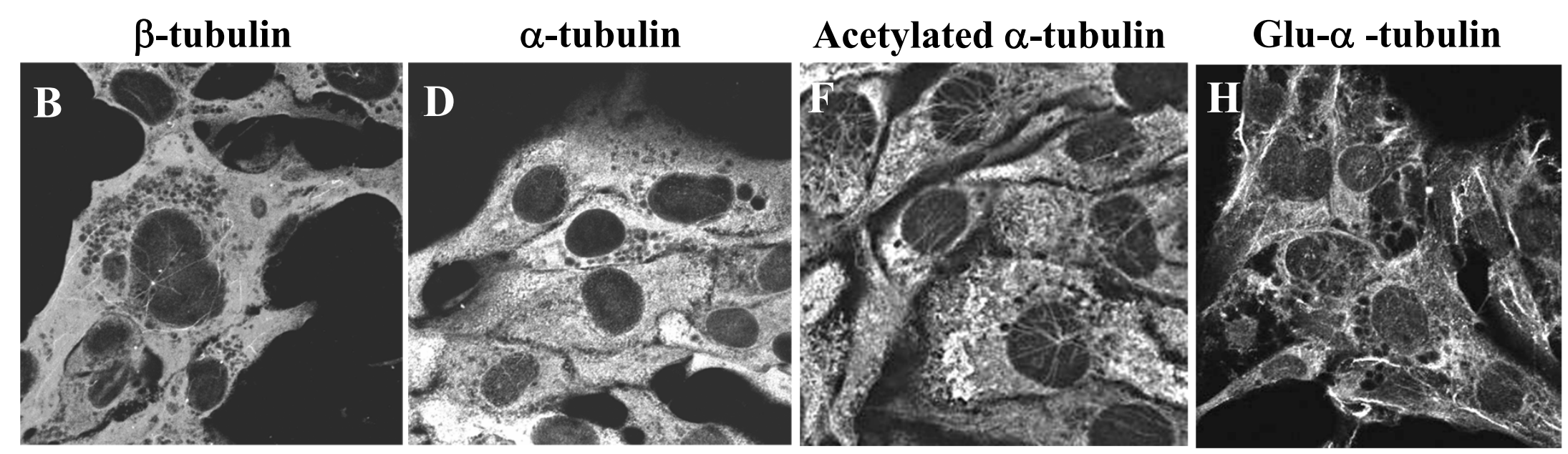

Figure 8 